\title{
Tensile deformation behavior of Al-Cu 206 cast alloys near the solidus temperature
}

\author{
Amir Bolouri ${ }^{1,}$ a and X.-Grant Chen ${ }^{1, b^{*}}$ \\ ${ }^{1}$ Department of Applied Sciences, University of Québec at Chicoutimi, \\ 555 boul. de l'Université, Saguenay, Québec, CANADA, G7H 2B1 \\ a amir.bolouri@brunel.ac.uk, amir.bolouri@yahoo.com, ’’ XGrant Chen@uqac.ca
}

Keywords: Al-Cu alloys, semisolid tensile property, deformation.

\begin{abstract}
To study the micromechanics of semi-solid deformation, a modified experimental set-up is employed in Gleeble 3800 thermomechamical testing unit to achieve a uniform temperature distribution in partially remelted aluminum samples. The temperature variation in the vicinity of the target temperature was markedly reduced to one degree for a length of 4-5 $\mathrm{mm}$ in the middle of the tensile samples. Semi-solid tensile tests of Al-Cu 206 alloys were performed at different temperatures near solidus with a strain rate of $10^{-3} \mathrm{~s}^{-1}$, corresponding to the solid fractions between 1 and 0.95. The stress-displacement curves with different solid fractions were measured and analyzed. The microstructure and fracture surface of samples were examined by optical and scanning electron microscopes. The relation between the microstructural characteristics and tensile properties and fracture behavior of semi-solid 206 samples at high solid fraction were explored. Mush deformation mechanisms were discussed in terms of defect nucleation and propagation at the latest stage of solidification.
\end{abstract}

\section{Introduction}

Casting defects such as hot tearing and porosity are closely related to the tensile stresses arisen from thermal gradient and solidification contraction during casting process [1][2][3][4]. Indeed, when the solidifying microstructure (mush structure) is exposed to the tensile stresses, its response will control the formation of the casting defects. On the other hand, the response of mush structure greatly depends on the volume fraction of liquid within the mush structure [5]. For solid fractions less than 0.85 , the interdendritic region is fairly open and the liquid phase within the mush structure will flow without difficulty and accommodate the exposed tensile stresses. For the solid fraction toward 0.95-0.98, the mush will be in its most critical region that the liquid phase cannot flow and feed within the mush structure spelling the formation of casting defects [5].

It has been generally reported that the semisolid tensile test can generate stress-strain conditions similar to the states caused during an actual solidification of aluminum alloys [4][6]. Several experimental set-ups have been recently developed [6][7][8]. However, a uniform temperature distribution profile within 5-6 mm along the specimen length should be obtained to ensure that the test is conducted with a minimum variation in liquid/solid contents. The tensile behavior of the mush as a function of solid fraction has been the subject of a number of studies [9][10]. However, there is limited information on the effect of the constitutive phases such as Fe-rich intermetallics on the semisolid tensile properties of aluminum alloys during the last stage of solidification. The morphology, size and distribution of intermetallics are crucial to the resulting casting defects such as hot tearing [11].

In the present study, a modified experimental set-up and a heating regime to achieve a uniform temperature distribution for the semisolid tensile tests was proposed. A sensitivity analysis was conducted. Subsequently, for the liquid fractions less than 0.1 (near the solidus), the semisolid tensile tests were conducted on two Al-Cu 206 alloys with different Fe-rich intermetallics. The effects of different iron-rich intermetallics on the tensile properties of the mush were thoroughly examined. The crack propagation mechanisms within the mush structure at different liquid fractions have been examined and discussed. 


\section{Experimental Procedures}

Two Al-4.5Cu alloys with different Fe-rich intermetallic phases [12][13] were investigated. Alloy 311 with $0.1 \% \mathrm{Si}$ and $0.1 \% \mathrm{Mn}$ has prodominant plate-like $\beta$-Fe (Al7CuFe) intermetallics in the microstructure, while Alloy 333 containing $0.3 \% \mathrm{Si}$ and $0.3 \% \mathrm{Mn}$ possesses mainly Chinese script $\alpha-\mathrm{Fe}\left(\mathrm{Al}_{5}(\mathrm{FeMn})_{3}(\mathrm{SiCu})_{2}\right)$ intermetallics. The chemical compositions of the alloys analyzed by optical emission spectroscopy are shown in Table 1.

Table 1. Chemical compositions of Al-Cu 206 alloys.

\begin{tabular}{|c|c|c|c|c|c|c|c|}
\hline \multirow[b]{2}{*}{ Alloys } & \multicolumn{6}{|c|}{ Elements [wt Pct] } & \multirow[b]{2}{*}{ Solidus $\left[{ }^{\circ} \mathrm{C}\right]$} \\
\hline & $\mathrm{Cu}$ & $\mathrm{Mg}$ & $\mathrm{Fe}$ & $\mathrm{Si}$ & $\mathrm{Mn}$ & $\mathrm{Al}$ & \\
\hline 311 & 4.69 & 0.31 & 0.32 & 0.11 & 0.12 & Bal. & 530 \\
\hline 333 & 4.64 & 0.33 & 0.34 & 0.32 & 0.33 & Bal. & 517 \\
\hline
\end{tabular}

The melting was conducted using an electric resistance furnace. The temperature of melt was held at $750{ }^{\circ} \mathrm{C}$ and the argon degassing was performed for 20 minutes. A standard ASTM B108 permanent mold, preheated at $350{ }^{\circ} \mathrm{C}$, was used to cast the as-cast samples. For semisolid tensile testing, cylindrical specimens with a total length of $120 \mathrm{~mm}$ and a diameter of $10 \mathrm{~mm}$ were machined from the ASTM B108 cast samples.

The Gleeble 3800 thermomechamical testing unit was used for semisolid tensile testing. Each specimen was fixed in a horizontal orientation between two grips and covered by a free movable ceramic tube (Fig. 1(a)). The specimen was rapidly heated via electro-resistance heating. Due to the heat loss at the end of specimen through the water-chilled grips, there is an asymmetric parabolic temperature profile along the specimen length that the hottest area occurs in the middle of the specimen [7]. The temperature was monitored by three K-type thermocouples spot-welled at the middle and at two sides with a distance of $\pm 8 \mathrm{~mm}$ from the middle (Fig. 1(a)). A two-step heating was conducted with the first step heated to $450{ }^{\circ} \mathrm{C}$ with a heating rate of $2^{\circ} \mathrm{C} / \mathrm{s}$ and held for $45 \mathrm{~s}$. The second step of heating was continued up to $5-7{ }^{\circ} \mathrm{C}$ below the target temperature and fine adjustment in a small increment to the target temperature held for $30 \mathrm{~s}$.

During the heating of the specimen, one grip is free to move to tolerate thermal expansion while another grip is always fixed. The full contact between coupler and the ram is secured immediately after the heating process was terminated. Subsequently, the force and displacement were set at zero and the tensile testing was commenced at a strain rate of $\sim 10-3$. The tensile tests were first conducted for fully solid state of the alloys at a temperature just below the solidus. Subsequently, with 2 degree increments in the test temperatures, the semisolid tensile tests were conducted. The increment in the temperature continued to a maximum temperature that a negligible value of fracture stress was obtained, which corresponded to a fraction solid fs of $\sim 0.9$. A minimum of 3 tests were conducted at each temperature. Differential scanning calorimeter (DSC) analysis was performed to determine the solid fraction vs temperature curves of two experimental alloys.

\section{Results and Discussion}

\section{Temperature Distribution Sensitivity Analysis}

The sensitivity analyses were conducted for a target temperature of $524{ }^{\circ} \mathrm{C}$ at the middle point of the specimens. For each test, the temperatures were monitored through thermocouples located at three points: one at middle (for the target temperature) and two at both sides with same distances from the middle, as shown in Fig. 1(a).

Typical temperature profiles along the length of specimens are shown in Fig. 1(b). Asymmetric parabolic temperature profile is clearly evident along the sample. Through different measures in adjusting the set-up, the maximum temperature drop in the vicinity of the target temperature is reduced to one degree in the hot middle region of $4-5 \mathrm{~mm}$. The measurements closer to the middle point of the specimen at $\pm 5 \mathrm{~mm}$ demonstrated to the results (Fig. 1(b)), to ensure a uniform temperature distribution in the hottest middle zone of the specimen during the tensile deformation. 
The achieved uniform temperature distribution in the hot middle zone of the specimen is due to the unique test set-up designed in this study. The main set-up feature is the application of the ceramic tube. It is suggested that the ceramic tube isolates the hot zone of the specimen and reduce the heat transfer, particularly trough the radiation. In addition, the second step heating plays a critical role that a slow heating rate at the final stage reduces the temperature differences along the hot zone.

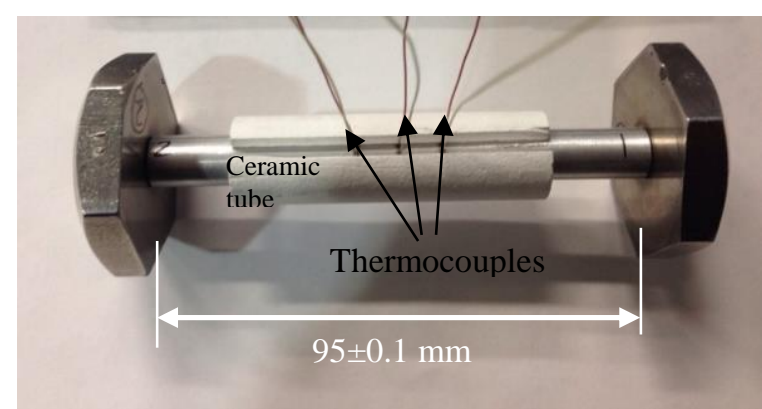

(a)

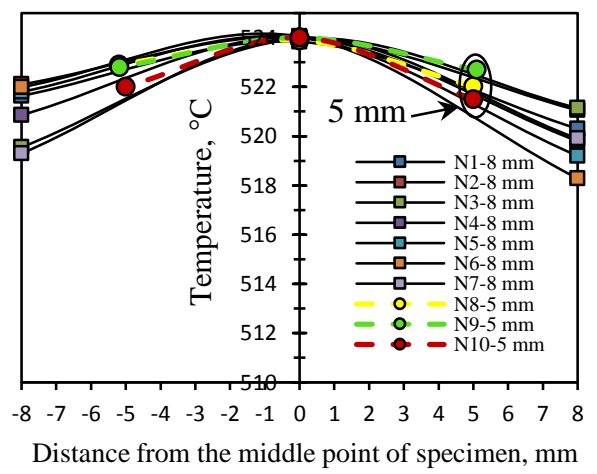

(b)

Fig. 1 (a) Image for specimen configuration and the position of thermocouples and (b) temperature distribution profiles along the length of specimens.

\section{As-cast Microstructure}

As-cast microstructures of 311 and 333 alloys are shown in Fig. 2. For 311 alloy, the microstructure consists of mainly needle-like $\beta$-Fe $\left(\mathrm{Al}_{7} \mathrm{CuFe}\right)$ intermetallics while for 333 alloy, their predominant Fe-rich intermetallics are the Chinese script $\alpha$-Fe $\left(\mathrm{Al}_{15}(\mathrm{FeMn})_{3}(\mathrm{SiCu})_{2}\right)$. Furthermore, in the microstructure of 311 alloy, $\beta$-Fe is markedly interlocked with low melting $\mathrm{Al}_{2} \mathrm{Cu}$ phase. On the contrary, for 333 alloy, $\mathrm{Al}_{2} \mathrm{Cu}$ and $\mathrm{Al}_{2} \mathrm{Cu}+\mathrm{Mg}_{2} \mathrm{Si}$ phases are freely distributed within the interdendritic regions. It is of importance to mention that the transformation of plate-like $\beta$-Fe to Chinese script $\alpha-\mathrm{Fe}$ is due to the increase of $\mathrm{Mn}$ and $\mathrm{Si}$ levels in the 333 alloys compared to the 311 alloy. The detailed mechanism for this transformation is explained in Ref [12].

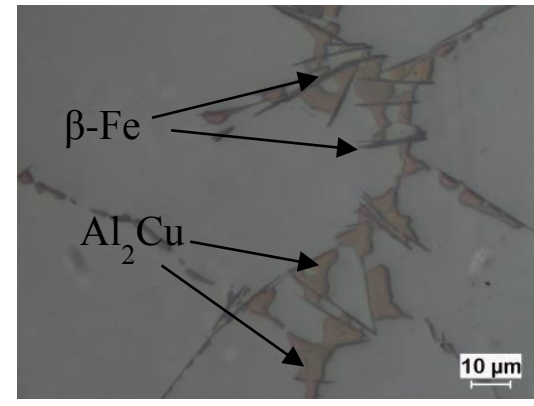

(a)

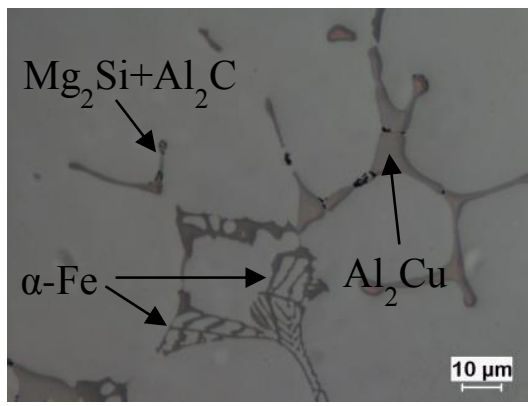

(b)

Fig. 2 As-cast microstructures of samples (a) 311 and (b) 333 alloys.

\section{Stress-Displacement Analysis}

Typical stress-displacement curves for 311 and 333 alloys at the selected liquid fractions of the mush structure are shown in Fig. 3. Independent from the type of the alloy, at the temperature very close to solidus temperatures as the mush contains very low amount liquid content of $\sim 0.02 \%$ (Error! Reference source not found.(a)), the structure accommodates plastic deformation before the fracture. The plastic deformation is due to the presence of large fraction of solid grain skeletons [5]. Further increase in the liquid content results in a brittle fracture of the mush without any plastic deformation (Figs. 3(b) and (c)). This type of fracture can be attributed to decohesion between grains and the fracture occurred as a result of intergranular openings. By increasing the liquid content, the fracture stresses and displacements consciously reduce for both alloys up to liquid contents of $\sim 3 \%$. Above $3 \%$ liquid content, both alloys show the similar tensile properties although 
the fracture displacements are slightly different. It could be proposed that above this critical liquid content of $\sim 3 \%$, the fracture is ruled by liquid phase exhibiting similar characteristics for both alloys [8].

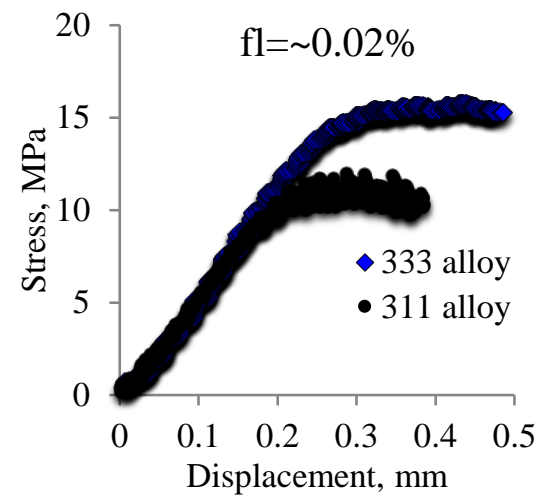

(a)

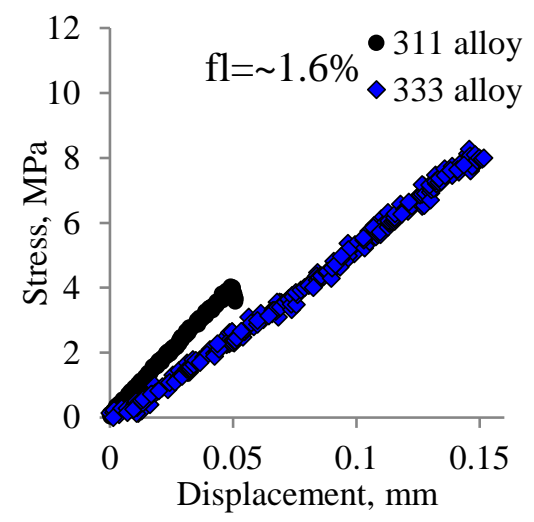

(c)

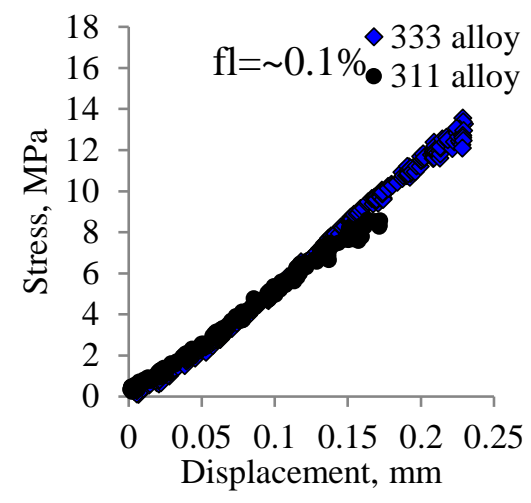

(b)

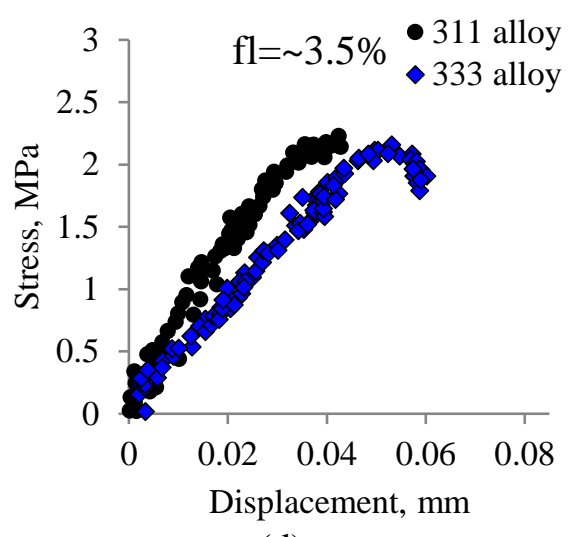

(d)

Fig. 3 Stress-displacement curves for 311 and 333 alloys at different liquid fractions.

As shown in Error! Reference source not found. ( $a, b$ and $c$ ), for liquid contents less than $~ 3 \%$, 311 alloy exhibits lower tensile properties compared to 333 alloy. The lower fracture stress could be explained by considering the needle-like $\beta$-Fe acting as stress concentration points within the semisolid microstructure. On the other hand, it has been generally suggested in the literature that the displacement to the fracture of a mush is a function of liquid feeding within the structure [5][8][10]. When the liquid easily flows within the mush and feeds the regions being deformed, the structure will accommodate further resulting in larger displacement to the fracture. Therefore, it could be suggested that the liquid feeding within the mush structure of 311 alloy is more limited compared to 333 alloy.

Fig. 4 shows the stress and displacement as a function of time in tensile test for both alloys. It is clear that the maximum displacement occurs earlier for 311 alloy compared with 333 alloy. More importantly, compared to 333 alloy, the increase in stress is considerably sharper in 311 alloy. Specifically, for 333 alloy, the stress reached its maximum of $10.3 \mathrm{MPa}$ in $1.67 \mathrm{Sec}$ while the maximum stress of $8.6 \mathrm{MPa}$ occurred after $0.78 \mathrm{Sec}$ for 311 alloy. By considering that the maximum stress is reached when the damage within the much structure is fully expanded, it is expected that the damage expands faster in the microstructure of 311 alloy.

\section{Crack Propagation}

To study crack propagation within the semisolid microstructures of the alloys, a new set up of experiments has been conducted that the applied tension was stopped at the displacement of $0.06 \mathrm{~mm}$ for the semisolid specimens with liquid content of $3 \%$, avoiding full fracture of the specimens. Subsequently, the unfractured specimens were dismounted from the Gleeble machine and sectioned for microstructural observations. Fig. 5 shows the longitudinal observations of crack 
path within the semisolid microstructure of the unfractured samples. An intergranular opening within the semisolid microstructure is apparent for both alloys (Fig. 5(a)). It appears that for both alloys, the crack propagates through the low melting $\mathrm{Al}_{2} \mathrm{Cu}$ phase located along the grain boundaries.

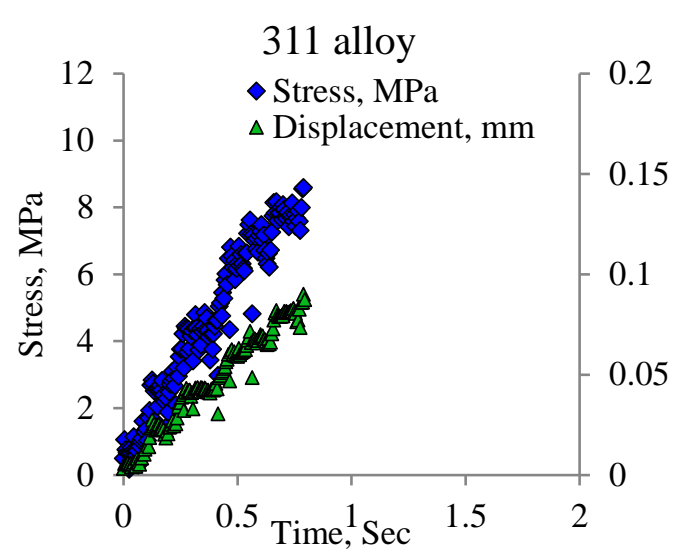

(a)

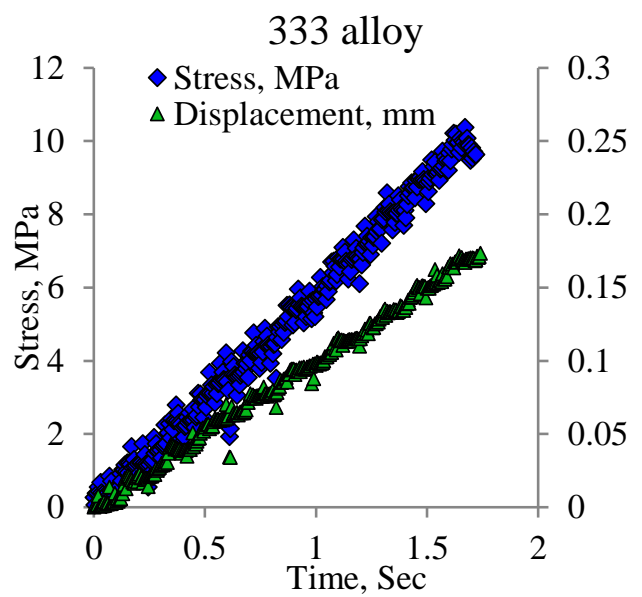

(b)

Fig. 4 stress and displacement variation as a function of time in the semisolid tensile test for the alloys at the liquid contents of $\sim 0.4 \%$.

The morphologies of iron-rich intermetallic phases are of critical importance on the crack propagation. For 333 alloy, Chinese script $\alpha$-Fe is the last phase to be fractured (Fig. 5(b)) while for 311 alloy, the crack paths are dominantly along $\beta$-Fe (Fig. 5(c)). Clearly, as shown in Fig. 5(c), the plate-like $\beta$-Fe provides the easier path for the cracks to propagate. The effect of different Fe-rich intermetallics on the semisolid tensile properties is also reflected in stress-time curve shown in Fig. 4. As $\beta$-Fe appears to accelerate the crack growth within the semisolid microstructure, the damage expansion is faster for the semisolid 311 alloy.

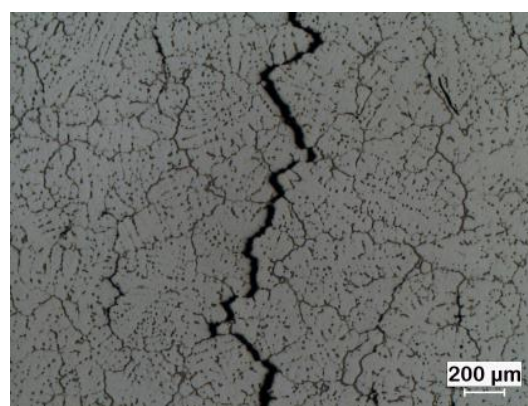

(a)

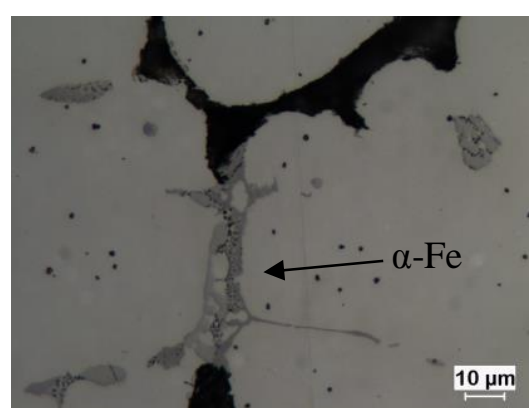

(b)

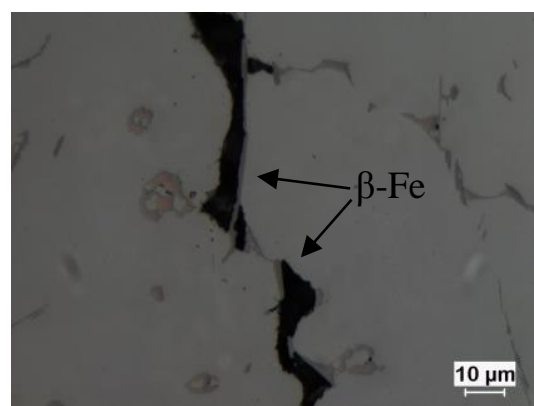

(c)

Fig. 5 The longitudinal observations of crack path (a) typical intergranular opening, (b) 333 alloy and (c) 311 alloy at liquid content of $3 \%$ and $0.06 \mathrm{~mm}$ displacement.

The propagation of the cracks may occur due to either flow or rupture of the low melting $\mathrm{Al} 2 \mathrm{Cu}$ liquid [3]. In Error! Reference source not found.(a), as the liquid phase is very thin $\sim 1 \mu \mathrm{m}$ (a fairly low amount of interdendritic liquid phase is present), the crack appears to progress through the rupturing of liquid phase. However, for the grain boundary with a larger pool of liquid, the liquid phase will flow (Error! Reference source not found.). During the semisolid tensile test, since there is no external liquid feeding, the liquid flows to compensate the deformation within the semisolid microstructure. In other words, the liquid is sucked into the region being deformed [14]. This will result in the formation of pores and consequently, the propagation of the cracks [15]. The liquid phase between two grains (interdendritic liquid phase) is being stretched during the application of the tension and formed meniscuses. Therefore, the pores are nucleated because the 
volume of the liquid remains constant. Upon further stretching during semisolid tensile, the meniscuses will break and move due the loss of surface tension equilibrium in the breakage.

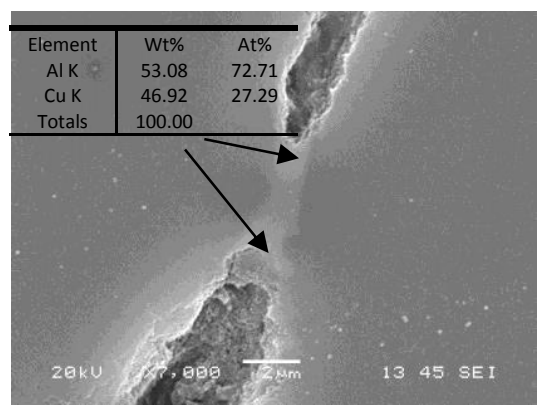

(a)

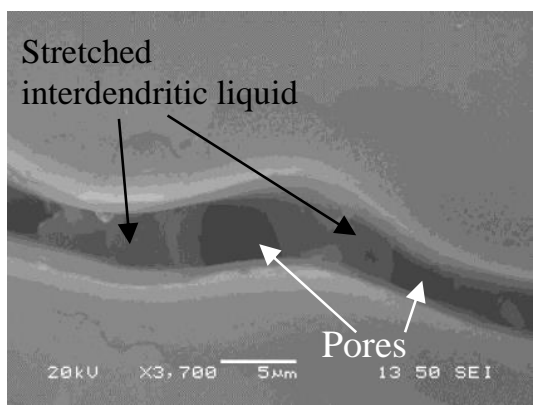

(b)

Fig. 6 (a) SEM image of a progressive crack and composition at the tip of the crack (311 alloy at fl $\sim 3 \%$ ) and (b)SEM image for the stretched interdendritic liquid phase and pores (333 alloy at $\mathrm{fl}$ $\sim 3 \%)$.

Figure demonstrates the longitudinal observations of mush structure containing very small liquid content of $<0.1 \%$ after the tensile displacements of 0.06 and $0.08 \mathrm{~mm}$. Unlikely to the high liquid contents that the liquid flow may occur, it appears that the crack initiation and propagation mechanisms are different at very low liquid fractions. It can be clearly seen that the pores nucleate from incipient melting of $\mathrm{Al}_{2} \mathrm{Cu}$ phase at grain boundaries and triple points (Figure ). However, there is very rear evidence for the opening of pores after the tensile displacement of $0.06 \mathrm{~mm}$, contrasting with the mush containing $~ 3 \%$ liquid content that a full intergranular opening occurred (Fig. 5(a)). Further increase in the tensile displacement of $0.08 \mathrm{~mm}$ results in the progress of cracks through the initial pores at incipient melting (Figure ). It is observed that a considerable amount of solid phase plastic deformation occurs during crack propagation, confirmed in the stressdisplacement curve shown in Error! Reference source not found.(a).

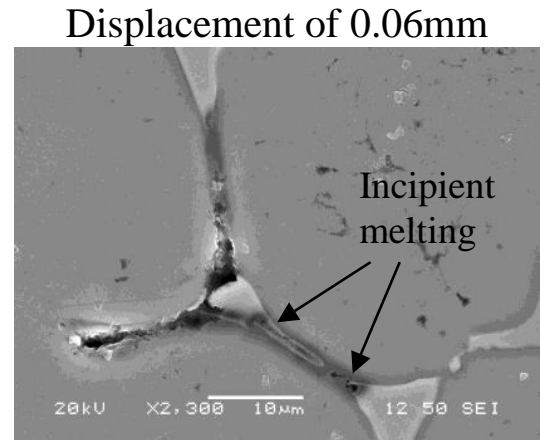

(a)

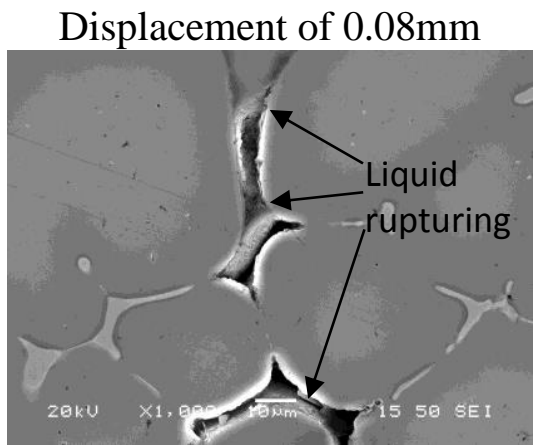

(b)

Figure 7 The longitudinal observations of crack nucleation and propagation for 333 alloy at low liquid content of $<0.1 \%$.

\section{Conclusions}

1. For the liquid contents less than $\sim 3 \%$, the semisolid tensile properties of the mush containing needle-like $\beta$-Fe (311 alloy) were considerably lower compared to the mush with less harmful Chinese-script $\alpha$-Fe (333 alloy) intermetallics. For the liquid contents higher than $\sim 3 \%$, the semisolid tensile properties were ruled by the liquid phase, resulting in similar tensile properties for both alloys.

2. The damage expanded faster in the mush structure of 311 alloy compared to 333 alloy. The rate of stress increase as a function of time was higher for 311 alloy than 333 alloy as the stress reached its maximum stress (fracture) in considerably shorter time.

3. Under semisolid tensile condition, the crack propagation was through low melting liquid along grain boundaries, resulting in an intergranular opening within the semisolid microstructure for 
both alloys. The liquid phase located at grain boundaries and triple points either was stretched or ruptured depending on the amount of liquid phase present.

4. For mush containing very low amount of liquid phase (less than $0.1 \% \mathrm{fl}$ ), the cracks initiated from the incipient melting points. In addition, the localized plastic deformation occurred within the mush.

\section{References}

[1] K. M. Kareh, P. D. Lee, R. C. Atwood, T. Connolley, and C. M. Gourlay, Revealing the micromechanisms behind semi-solid metal deformation with time-resolved X-ray tomography, Nat Commun. 5 (2014) 4464.

[2] A. B. Phillion, S. Thompson, S. L. Cockcroft, and M. A. Wells, Tensile properties of as-cast aluminum alloys AA3104, AA6111 and CA31218 at above solidus temperatures, Mater. Sci. Eng. A 497 (2008) 388-394.

[3] I. Farup, J. M. Drezet, and M. Rappaz, In situ observation of hot tearing formation in succinonitrile-acetone, Acta Mater. 49(2001) 1261-1269.

[4] D. G. Eskin, Suyitno, and L. Katgerman, Mechanical properties in the semi-solid state and hot tearing of aluminium alloys, Prog Mater Sci 49 (2004) 629-711.

[5] M. Rappaz, J.-M. Drezet, and M. Gremaud, A new hot-tearing criterion, Metall. Mater. Trans. A 30 (1999) 449-455.

[6] E. Giraud, M. Suery, and M. Coret, Mechanical behavior of AA6061 aluminum in the semisolid state obtained by partial melting and partial solidification, Metall. Mater. Trans. A Phys. Metall. Mater. Sci. 41(2010) 2257-2268.

[7] L. J. Colley, M. A. Wells, and D. M. Maijer, Tensile properties of as-cast aluminum alloy AA5182 close to the solidus temperature, Mater. Sci. Eng. A 386 (2004) pp. 140-148.

[8] D. Fabrègue, A. Deschamps, M. Suery, and J. M. Drezet, Non-isothermal tensile tests during solidification of $\mathrm{Al}-\mathrm{Mg}-\mathrm{Si}-\mathrm{Cu}$ alloys: Mechanical properties in relation to the phenomenon of hot tearing, Acta Mater. 54 (2006) 5209-5220.

[9] B. Cai, S. Karagadde, L. Yuan, T. J. Marrow, T. Connolley, and P. D. Lee, In situ synchrotron tomographic quantification of granular and intragranular deformation during semi-solid compression of an equiaxed dendritic Al-Cu alloy, Acta Mater. 76, (2014) 371380.

[10] A. B. Phillion, R. W. Hamilton, D. Fuloria, A. C. L. Leung, P. Rockett, T. Connolley, and P. D. Lee, In situ X-ray observation of semi-solid deformation and failure in Al-Cu alloys, Acta Mater. 59 (2011) 1436-1444.

[11] C. Puncreobutr, P. D. Lee, K. M. Kareh, T. Connolley, J. L. Fife, and A. B. Phillion, Influence of Fe-rich intermetallics on solidification defects in $\mathrm{Al}-\mathrm{Si}-\mathrm{Cu}$ alloys, Acta Mater. 68, (2014) 42-51.

[12] K. Liu, X. Cao, and X. G. Chen, Effect of Mn, Si, and cooling rate on the formation of ironrich intermetallics in $206 \mathrm{Al}-\mathrm{Cu}$ cast alloys, Metall. Mater. Trans. B Process Metall. Mater. Process. Sci. 43 (2012) 1231-1240.

[13] K. Liu, X. Cao, and X.-G. Chen, Solidification of Iron-Rich Intermetallic Phases in Al4.5Cu-0.3Fe Cast Alloy, Metall. Mater. Trans. A Phys. Metall. Mater. Sci. 42 (2010) 20042016.

[14] M. Sistaninia, A. B. Phillion, J. M. Drezet, and M. Rappaz, A 3-D coupled hydromechanical granular model for simulating the constitutive behavior of metallic alloys during solidification, Acta Mater. 60 (2012) 6793-6803.

[15] M. Sistaninia, S. Terzi, a. B. Phillion, J. M. Drezet, and M. Rappaz, 3-D granular modeling and in situ X-ray tomographic imaging: A comparative study of hot tearing formation and semi-solid deformation in Al-Cu alloys, Acta Mater. 61, (2013) 3831-3841. 